\title{
DECISÕES ENTRE PESQUISAS QUALI \\ E QUANTI SOB A PERSPECTIVA DE \\ MECANISMOS CAUSAIS*
}

\section{Charles Kirschbaum}

\section{Introdução}

Os intermitentes "debates paradigmáticos" na sociologia são constitutivos do campo. Como já apontado por Lee e Wallerstein (2000), a sociologia encontra-se entre as ciências naturais e as humanidades, e provavelmente nunca obteremos ou desejaremos um consenso epistemológico. Os debates paradigmáticos não se referem apenas aos pressupostos epistemológicos (condições de aquisição de conhecimento), mas traz aspectos normativos na aquisição e utilização do conhecimento. Ao mesmo tempo em que os debates paradigmáticos encontram esforços de sínteses e discussões metateóricas

* Agradeço Eduardo Marques, Renata Bichir, Nadya Guimarães e Sérgio Lazzarini pelas discussōes que me levaram à elaboração deste texto. Gostaria de dedicá-lo aos meus orientandos.

Artigo recebido em 12/01/2011

Aprovado em 03/04/2013 (ver, por exemplo, Alexander, 1987), o sentimento de fragmentação persiste (Ianni, 1990). De forma correlata, os desencontros paradigmáticos são traduzidos para embates entre métodos (Cano, 2012). Nesse artigo, reforço a ideia de que a escolha de método não é univocamente ligada à escolha paradigmática. Seguindo nessa linha de pensamento, abordo a questão de escolha de método sob a abordagem de "mecanismos causais". A escolha de um escopo reduzido é proposital: ao mesmo tempo em que a escolha dessa abordagem ilustra bem a possibilidade de combinação de métodos, ela mantém nossa discussão focada, permitindo aprofundamento. Ao final do artigo, retornarei a essa escolha basilar, remetendo aos possíveis desenvolvimentos e conexôes com outras abordagens.

A escolha de entre métodos quali e quanti é em geral subordinada à discussão entre paradigmas de construção de conhecimento nas ciências sociais, levando frequentemente a dogmatismos: "Pior ainda 
do que as críticas infundadas ou parciais de que quantitativo-qualitativo é um binômio antitético, perante o qual é preciso optar" (Cano, 2012, p. 115). Pesquisas quali são tradicionalmente associadas a interesses de pesquisa tipicamente subjetivistas. Em contraste, pesquisas quanti geralmente respondem às exigências do paradigma "positivista", ${ }^{1}$ cujo interesse de pesquisa é centrado no estabelecimento de leis causais.

Manicas (2006) identifica os "mecanismos causais" como uma abordagem central para a proposição e o estabelecimento de relações causais. Sob essa perspectiva, a escolha de metodologias quali pode ser subordinada às necessidades de estipulação de relações causais, nem sempre possíveis a partir de abordagens quanti. Esse artigo busca repensar a escolha de método a partir do pressuposto adotado por uma comunidade crescente de pesquisadores em ciências sociais.

A discussão sobre "mecanismos causais" tem sido expandida nas ciências sociais (Tilly, 2001; Mahoney e Goertz, 2006; Ragin, 2006; Gerring, 2007; Przeworski, 2007; Hedström e Ylikoski, 2010) devido à tentativa de reconciliar a abordagem histórica com a identificação de leis universais. $\mathrm{Ou}$ seja, cientistas sociais buscam construir conhecimento que seja a um só tempo "histórico" e "científico generalizável". A abordagem "histórica" é necessária à ciência social porque eventos únicos e raros como revoluçôes podem ser explicados como resultado da combinação de uma série de processos que se desenvolvem em paralelo e em longos períodos de tempo (Sewell, 2005). Mas ao contrário dos historiadores, os cientistas sociais buscam encontrar padrōes que possam tornar generalizável o entendimento dos processos (Goldthorpe, 2007).

A necessidade de posicionar a abordagem histórica-processualista como central no estabelecimento, na revisão e no aprimoramento dos mecanismos causais produz dois efeitos importantes. Em primeiro lugar, é possível repensar os desenhos de pesquisa que se propōem a estabelecer estruturas causais para que introduzam abordagens quali. Por outro lado, podemos rever a percepção cristalizada entre vários pesquisadores de que toda pesquisa quali é necessariamente destituída de interesse explicativo causal. Corroborando a afirmação de Manzo (2010), não é produtivo manter a percepção de uma relação unívoca de paradigma e método. Especificamente, esse artigo aprofunda a discussão sobre a necessidade do uso de métodos quali em pesquisas que almejam a construção de mecanismos causais ao identificar instâncias onde as pesquisas quanti produzem resultados ambíguos ou de difícil interpretação. Em contraste com uma visão demasiadamente simples da relação entre "paradigma", "questão de pesquisa" e "escolha de método", busco mostrar a importância de rever esses vínculos.

Esse artigo está estruturado da seguinte forma. Recupero brevemente o debate entre pesquisadores que adotam abordagens qualitativas e quantitativas, demarcando clivagens e tentativas de síntese. A seguir, introduzo a perspectiva de "mecanismos causais" que orientará a discussão subsequente. $\mathrm{Na}$ seção seguinte recupero a discussão de escolha de metodologia, agora informada pela ideia de mecanismos causais. Ofereço exemplos de metodologias mistas recentemente desenvolvidas que respondem a essa perspectiva. Por fim, retorno à escolha de "mecanismos causais" como uma forma produtiva de discutir a decisão de método.

\section{Paradigmas e métodos}

O embate entre métodos quanti e quali acompanha matizes distintas de oposiçóes entre abordagens teóricas na sociologia. Nessa seção, abordo algumas das clivagens e debates. Uma das abordagens mais tradicionais é associada ao choque entre as perspectivas "positivistas" e "interpretacionistas", nascidas no século XIX (Ringer, 2000; Cano, 2012). ${ }^{2}$ Enquanto os primeiros insistiam em comparabilidade e estabelecimento de leis universais e neutras em relação ao objeto, os últimos defendiam a especificidade dos casos. Tentativas de síntese eram, antes de tudo, rejeitadas com justificativas ideológicas (Skidelsky, 2009). ${ }^{3}$

Podemos localizar nos estudos da sociologia da ciência tentativas de abordar qualitativamente fenômenos tradicionalmente tratados de forma quantitativa, enfraquecendo a promessa da abordagem positivista de neutralidade científica (Knorr-Cetina, 1981). Knorr-Cetina aponta para três formas 
de argumento nessa linha: negação da aceitação de fatos brutos (ou seja, todos os fatos são construídos através de lentes teóricas, ver Knorr-Cetina e Mulkay, 1983), evidência de circularidade nas interpretaçôes (isto é, conceitos gerados por cientistas sociais passam a circular na sociedade, alterando o fenômeno orginalmente observado, ponto trazido por Giddens) e a possibilidade de interpretação vinculada a um contexto específico (o que pode ser também relacionado com o relativismo epistemológico). Recuperando ideias do realismo crítico, Knorr-Cetina aponta o problema de localização da causalidade em fatos externos à ação humana.

Desse ponto de vista, obteríamos uma convivência entre as abordagens, mas com baixa pretensão de desenvolvimento de desenhos mistos. Esse tipo de posicionamento fica evidente na abordagem etnometodológica, em que os agregados estatísticos são tomados como irrelevantes para a ação humana, ao buscar-se o entendimento de como os indivíduos dão significado para sua ação (Coulon, 1995). Assim, em algumas abordagens há uma separação de trabalho tácita - pesquisas quantitativas abordariam questóes ligadas aos constructos tradicionais ligados à estrutura, enquanto pesquisas qualitativas estariam mais ligadas à agência.

Essa "separação de trabalho" é revista e desafiada por várias abordagens de cunho metodológico e teórico. Do ponto de vista metodológico, podemos identificar trabalhos que evidenciam a necessidade dos estudos quantitativos complementados por estudos qualitativos, com o objetivo de aumentar a validade de seus constructos (Abbott, 2001; Collins, 1984), ou melhor, especificar os pressupostos "agênticos" da teoria (Goodwin e Horowitz, 2002). Uma estratégia alternativa tem sido rever e propor sínteses teóricas que informem novas abordagens metodológicas (Alexander, 1987). Por exemplo, Bourdieu discute os limites da abordagem de história de vida quando essa não é informada pelo constructo "campo", frequentemente operacionalizado de forma topográfica (Bourdieu, 1986, 2006).

No debate nacional, esses posicionamentos ganham interlocutores que traduzem essas clivagens para a nossa realidade. ${ }^{4} \mathrm{~A}$ consulta a livros-textos de metodologia de pesquisa em ciências sociais revela a herança da dicotomia entre as perspectivas positi- vista e interpretacionista na orientação das escolhas de método. Em muitos casos, os autores apresentam os paradigmas de construção de conhecimento como logicamente antecedente da escolha de método. Pesquisas quali são percebidas como adequadas a uma abordagem em que o foco do trabalho recai sobre a investigação do ponto de vista subjetivo dos indivíduos e suas formas de interpretação do meio social onde estão inseridos (Denzin e Lincoln, 2005). Caracterizam-se por estudos flexíveis, menos estruturados, em que as descobertas de campo levam a desdobramentos que guiam o pesquisador em seus passos (Ragin e Becker, 1992). Em contraste, as pesquisas quanti, reconhecidas como adequadas ao paradigma positivista, calcam-se sobre a dedução de hipóteses oriundas da teoria estabelecida. Dessa forma, o material coletado deve ser mensurado e condensado em variáveis. A comparação da variação das variáveis de interesse permite ao pesquisador o estabelecimento de leis gerais sobre $\mathrm{o}$ comportamento social.

Em contrapartida, a dicotomia entre quali e quanti é vista com suspeita por vários autores, levando à busca de pontes entre os dois campos (Morgan, 2007). Vários autores sugerem que essas abordagens não são excludentes e que o pesquisador deve adotar uma postura flexível, considerando uma possível integração entre pesquisas quanti e quali (Teddlie e Tashakkori, 2003). É digno de nota, por exemplo, a defesa que Bourdieu faz da utilização de métodos quantitativos como lacuna nos estudos da sociologia crítica (Bourdieu, Chamboredon e Passeron, 2004).

É possível verificar nesta discussão que o debate em torno do método a ser utilizado é frequentemente ligado à discussão teórica, mas cabe o questionamento se essa vinculação deve ser unívoca, de tal forma que a escolha teórica incorra necessariamente em uma especialização em método. Por exemplo, se o pesquisador dedica-se ao estudo de desigualdade, isso significa que deverá aprender (e apreciar) apenas métodos quantitativos? De forma correlata, se um pesquisador dedica-se a fenômenos da microssociologia (na linha de Goffman, por exemplo), isso significa que poderá simplesmente descartar as disciplinas de estatística? Como vimos, dependendo do paradigma adotado, a resposta é 
"sim" para ambas as questões. No entanto, acredito que certos interesses de pesquisa e orientaçôes paradigmáticas colocam-se de forma mais agnóstica em relação ao método.

Camic e Gross (1998) mostram que o desenvolvimento da sociologia não se reduz à síntese, ao refinamento, à expansão, dissolução ou recuperação de teorias. Paralelamente, sociólogos constroem ferramentas metodológicas para utilização nas análises empíricas e travam diálogo entre abordagens distintas. A abordagem de mecanismos causais está ligada à tradição mertoniana de construção de médio-alcance. Embora tenha ganhado maior afinidade com a teoria de escolha racional, desenvolvimentos recentes mostram que a abordagem de mecanismos não se reduz a essa abordagem (Gross, 2009; Little, 2012). A proposta de mecanismos causais busca propor a construção de teorias que possam fornecer explicações causais e ao mesmo tempo evitar a abordagem positivista tradicional de elaboração de leis universais. Defensores desse ponto de vista argumentam que os mecanismos causais podem incluir na explicação elementos interpretacionistas (Gross, 2009).

\section{Quali e quanti sob a perspectiva de mecanismos causais}

Tilly (2001) avalia criticamente cinco possíveis posicionamentos metateóricos para o pesquisador, sendo os quatro primeiros alternativos à abordagem de mecanismos causais: adotar uma posição de ceticismo, construir leis gerais, construir um sistema social, estudar a predisposição do ator antes da observação do comportamento e estabelecer mecanismos e processos. A discussão a seguir expande a exposição de Tilly. Os três pressupostos que antecedem a proposição focada em mecanismos são derivados da discussão dos posicionamentos metateóricos.

A primeira posição refere-se ao ceticismo em relação à construção de conhecimentos que tenham alcance fora de seu contexto particular. Pesquisadores guiados por essa posição tendem a afirmar a impossibilidade de comparação, levando ao particularismo máximo das observações. Embora essa abordagem seja criativa em trazer fenômenos des- viantes às teorias, Tilly aponta que ela não tem a pretensão de criar teorias que possam transcender o local e temporal. Nesse sentido, impõe-se um hiato entre a explicação causal e a interpretação do significado da ação social (Verstehen) (Manicas, 2006, p. 10). Essa posição radicaliza a abordagem interpretativista descrita anteriormente. Este artigo faz uma escolha explícita e arbitrária a favor de pesquisas que se afastam desse posicionamento. Portanto é possível estabelecer o primeiro pressuposto, em contraste com a posição "cética" exposta por Tilly.

\section{Primeiro Pressuposto: A construção de teoria pressupõe a possibilidade de comparação}

A posição relativa à construção de leis gerais, tipicamente associada à perspectiva positivista, busca a descoberta de regras que possam cobrir um grande número de casos e, potencialmente, a totalidade de casos possíveis de serem observados (ver também DiMaggio, 1995, p. 391). Tilly alerta para o problema de se buscar leis universais (covering laws) nas ciências sociais que se assemelham à pretensão teórica das ciências naturais, visto que essa abordagem pode levar a uma abstração exagerada, correndo o risco de perder o poder de explicação, já que quando se perde o contexto original dos casos coletados (King, Keohane et al., 1994).

Segundo Pressuposto: A construção de teoria deve preservar a especificidade contextual dos fenômenos observados

A pretensão da construção de "sistemas sociais" aparentemente dá conta das limitações anteriores: inclui indivíduos e estruturas de uma forma ligada e interativa. $\mathrm{O}$ exemplo clássico de teoria social baseada em sistemas é a sociologia parsoniana (Parsons, 1951) e atende ao projeto de síntese defendido por Alexander (1987) e Camic e Gross (1998). A dificuldade consiste na explicação do status dos agentes no sistema: podemos conceber um "sistema social" com necessidades inerentes, como "integração", que demandam a existência de "funçōes latentes" acopladas à correta socialização dos atores sociais para que o sistema se reproduza? Os escritos de Parsons são sempre uma fonte inesgotável 
de exemplos. Na sugestão de que as mulheres devam frequentar cursos superiores mesmo que não tenham pretensão ou perspectiva de inserção no mercado de trabalho, porque servirão como um bom modelo (role model) para seus filhos (Parsons, 1959), o autor inverte os "sinais": deduz a motivação e a ação individual a partir das necessidades sistêmicas. Mas essa posição é de difícil sustentação por não incluir de forma completa as consequências inesperadas da ação (Merton, 1936). Uma possibilidade de atenuação dessa tendência é a articulação explícita entre os níveis distintos irredutíveis (Tilly, 2001). ${ }^{5}$

Tilly também aponta para o perigo de recortar a realidade de forma exageradamente reducionista e focada no indivíduo. De forma ilustrativa, Coleman (1990) busca entender como efeitos "macro" (por exemplo, "estrutura social") podem ser derivados a partir da agregação do comportamento de vários indivíduos. Vários de seus estudos empíricos geraram explicações de comportamento individual que mostravam uma pobre previsibilidade do comportamento macro em contextos diferentes daquele originalmente estudado. Em contrapartida, Elster (1994) sugere que a ação e a mudança social devem ser entendidas a partir da ação individual, e essas contextualizadas em mecanismos causais. Tal abordagem, geralmente associada ao individualismo metodológico, tem para Tilly a limitação de colocar cores muito fortes no indivíduo, sem dar a devida atenção às estruturas sociais que circundam o agente possibilitando a ação. Um contraexemplo é oferecido por Tilly ao analisar a obra de Theda Skocpol (1979) sobre os antecedentes de revoluções. Nesse estudo comparativo, Skocpol estabelece as condiçôes estruturais que permitem aos atores sociais promover uma revolução.

Em comparação a Elster, Tilly (2001) prende-se menos à ação individual e busca reintroduzir na explicação causal mecanismos que possam integrar fenômenos macro. Ele aponta três tipos de mecanismo causal: ambientais, cognitivos e relacionais. ${ }^{6}$ Sob a égide de "mecanismos ambientais", os pesquisadores utilizam termos como "desaparece", "retrai", "cresce", afetando a disponibilidade material de recursos para a ação individual e informando ao indivíduo as condições de ação no seu ambiente. A respeito de "me- canismos cognitivos", encontramos explicações que incluem termos como "interpreta", "classifica", aproximando-se da lógica do individualismo metodológico. Por fim, quanto a "mecanismos relacionais", Tilly aponta que se utilizam conceitos como "alianças", "ataques" etc. Esses tipos de mecanismo interagem entre si em processos sociais mais complexos e podem informar e ser informados pelos estudos das "pretensões teóricas" descritas anteriormente.

\section{Terceiro Pressuposto: Causalidade deve ser vinculada a mecanismos causais nos niveis ambientais, cognitivos e relacionais}

A partir dessa discussão, encaminhamo-nos para a definição e a apreciação de mecanismos causais. Gross sintetiza a definição mais usual:

Um mecanismo social é uma sequência ou conjunto de eventos sociais ou processos mais ou menos gerais analisados em um nível inferior de complexidade ou agregação, no qual em certas circunstâncias - alguma causa X tende a produzir um efeito $\mathrm{Y}$ no domínio das relações humanas. Essa sequência pode ou não ser reduzida analiticamente às ações desempenhadas (enact) pelos indivíduos, pode envolver processos causais instrumentais-formais ou substantivos e pode ser observada, não observada, ou à princípio não observável (2009, p. 364 , tradução do autor).

Essa definição abarca os seguintes pontos comumente articulados na literatura: mecanismos sociais medeiam a relação de causa e efeito entre dois fatores, desenvolvem-se em um horizonte temporal, são generalizáveis, ainda que em graus distintos, e necessariamente incluem elementos analisados em um nível de agregação abaixo do nível do fenômeno que queremos explicar. Este último aspecto criou um vínculo entre a abordagem de mecanismos sociais e a escola de Escolha Racional. No entanto, Little (2012) acredita que mecanismos no nível macro, sem desagregação ao nível micro geram boas explicações, na medida em que o pesquisador constrói suposições plausíveis em relação ao nível inferior. Em contrapartida, Gross (2009) sugere a 
expansão dessa definição para que os mecanismos sociais possam incluir uma abordagem de ação social que contemple claramente como grupos de indivíduos interpretam e dão sentido ao contexto e sua interação.

"Causalidade" implica o estabelecimento teórico de como um fator leva ou influencia (e não apenas "se correlaciona com") um comportamento observado. Um "mecanismo causal" implica a descrição da sequência de eventos que liga a causa (fator explicativo) ao comportamento. O exemplo ilustrativo a esse respeito é geralmente tomado emprestado de David Hume. ${ }^{7}$ Quando lançamos uma bola de bilhar contra a outra, somos capazes de observar diretamente o efeito da primeira sobre a segunda. O teste empírico de mecanismos causais com base no ferramental estatístico segue uma série de requisitos formais rígidos. Morgan e Winship (2007) estabelecem quatro critérios para avaliar a validade de um mecanismo causal que ligue o fator "X" a um fenômeno "Y":

R.i Todos os mecanismos causais $\mathrm{Zi}$ que ligam $\mathrm{X}$ a Y devem ser mensuráveis.

R.ii Zi devem ser caminhos causais necessários e suficientes entre X e Y.

R.iii Se Zi consistem em caminhos diferentes, então esses caminhos devem ser isolados.

R.iv Z é causado por X e não por nenhum outro fator espúrio.

Esses quatro requisitos são difíceis de sustentar em um desenho de pesquisa quanti, levando a muitos estudiosos do campo estatístico a abandonar a pretensão de articulação entre causalidade e generalização (Mahoney e Goertz, 2006). Gerring (2007) contrasta as abordagens quali e quanti em relação à estipulação de mecanismos causais, salientando as características e as limitaçôes de cada abordagem (Tabela 1). Seguindo a nomenclatura do autor, denomino de $\mathrm{N}$-pequeno os estudos quali e $\mathrm{N}$-grande para uma pesquisa quanti que compara muitos casos. A partir daí, retomo na próxima seção a decisão de método quali ou quanti, conside- rando as três possibilidades: (1) necessária "divisão de trabalho" entre as abordagens, (2) justaposição das abordagens na mesma pesquisa e (3) possível síntese entre as metodologias.

O estabelecimento de "mecanismos causais" remete à estipulação de causalidade. Entretanto, pesquisadores oriundos de tradiçôes quali frequentemente discordam dos pesquisadores de tradição quanti sobre os requisitos para a estipulação de "causalidade". Mahoney e Goertz (2006) mostram que enquanto pesquisadores quali buscam "causas para efeitos observados", 8 pesquisadores quanti buscam medir efeitos para as causas preestabelecidas. Essa diferença (respectivamente, "dos efeitos para as causas", ou "das causas aos efeitos") leva a diferenças importantes tanto na linguagem como no método.

Gerring sugere como primeira dimensão de comparação entre as duas abordagens a capacidade de gerar ou de testar hipóteses. Enquanto abordagens $\mathrm{N}$-pequeno levariam à geração de explicações (conexôes causais) novas, caberia às abordagens N-grande testar as hipóteses que operacionalizam as conexões causais através de variáveis. Nesta ilustração de "divisão de trabalho" entre as duas abordagens, somos convidados a visualizar a imagem de uma floresta: nos pontos onde a floresta ainda está inexplorada, caberia aos "bandeirantes qualitativos" desbravá-la e apontar novos caminhos e novas possibilidades. ${ }^{9}$ Ao passo que atrás desse primeiro grupo, seguiria um exército de pesquisadores quanti, empossados de ferramentas estatísticas que possam fornecer maior certeza, isto é, mais segurança para o que fora afirmado por seus antecessores.

Ao recuperar as dimensões de "validade" e "fonte de causalidade", Gerring alerta para motivos mais próximos das pretensões teóricas que alinhavei na seção anterior. Estudos de caso em $\mathrm{N}$-pequeno permitem a explicitação dos mecanismos causais que melhor se aproximam da explicação causal. A investigação de um estudo de caso busca, com alta intensidade de triangulaçôes de fatos e dados, o esgotamento m um determinado contexto. Em contrapartida, na medida em que o estudo esgota as fontes de explicação de um fenômeno específico e particular, obtemos uma trama de mecanismos que tornam as conclusões "determinísticas" em vez de "probabilísticas". Se o número de casos analisado 
Tabela 1

Comparação entre as Abordagens N-pequeno e N-grande de Gerring (2006), adaptado pelo autor

\begin{tabular}{lll}
\hline Dimensões & N-pequeno (quali) & N-grande (quanti) \\
\hline Objetivos de Pesquisa & & \\
\hline Explicação e Hipóteses & Gera explicações & Testa hipóteses \\
\hline Validade & Interna & Externa \\
\hline Fonte de Causalidade & Mecanismos causais & Efeitos causais \\
\hline Escopo das Proposições & Profundo & Amplo \\
\hline Fatores Empíricos & & \\
\hline População em Análise & Heterogêneo & Homogêneo \\
\hline Força da causalidade & Forte & Fraco \\
\hline Utilidade da Variação & Raro & Comum \\
\hline Disponibilidade de dados & Concentrada & Dispersa \\
\hline
\end{tabular}

for apenas um, todas as conexões causais se apresentarão como determinísticas e fortes. Quando se adicionam mais casos ao estudo é possível migrar para interpretações probabilísticas, e, portanto, a força de causalidade diminui. No procedimento de estudo de caso com conclusões determinísticas (ainda que o pesquisador adicione os usuais alertas para os limites à generalização), o que se busca é a validade interna do caso estudado ${ }^{10}$ : os mecanismos causais identificados e os processos históricos devem estar bem articulados na explicação do fenômeno de interesse.

Pesquisadores quali buscam identificar no estudo em questão as causas necessárias e suficientes para explicar um fenômeno de interesse. Condições necessárias devem estar presentes para que observemos um comportamento; entretanto, a simples presença delas não garante que o comportamento será observado. Assim, essas condições devem ser complementadas por outras, a fim de que sejam coletivamente necessárias e suficientes para explicar o comportamento. Em contraposição, condiçôes suficientes indicam um comportamento determinado, mas não são exclusivas: outros fatores podem levar ao mesmo comportamento.

Por outro lado, pesquisadores quanti buscam "efeitos causais" ao examinar a variação da variável dependente em relação à variação da variável independente. Por exemplo, se afirmamos que "baixo conflito" e "abundância de recursos" são condiçôes necessárias e suficientes para prever o crescimento de uma associação, isso não corresponde ao mesmo que operacionalizar em uma regressão múltipla os efeitos que grandezas de "conflito" e "recursos" teriam sobre a variável "crescimento". Como apontado por Sutton e Staw (1976, p. 377), não podemos confundir as hipóteses (que relacionam grandezas) com as explicações teóricas que sustentam a conexão dessas grandezas (em nossos termos, mecanismos causais). Abordagens $\mathrm{N}$-grande tendem a favorecer a "inferência causal", em que a causalidade é estabelecida pela diferença entre as estimativas de variação entre duas populações. Nesse tipo de desenho de pesquisa, uma delas é tomada como "controle". Ou seja, se o comportamento observado na população que sofreu algum tratamento específico for significantemente diferente do comportamento observado na população de controle, podemos então estabelecer a relação causal entre o tratamento e o efeito observado. (King, Keohane et al., 1994). Em outras palavras, a inferência causal busca estabelecer diferenças de "volumes" em variáveis mensuráveis e associar essa diferença à hipótese derivada da teoria que explica a diferença. A partir daí, têm-se a ideia de que a causalidade é estabelecida com base nos "efeitos causais" observados, ao passo que os mecanismos causais perdem a centralidade na análise. 
É no contraste entre pesquisas quali e pesquisas quanti e na diferenciação entre "mecanismos causais" e "efeitos causais" que melhor podemos observar o potencial de contribuição das abordagens quali aos estudos quanti. Por exemplo, em um texto clássico da "sociologia das organizações", Blau (1970) relaciona o aumento de "tamanho da firma" com a "diferenciação interna". No entanto, a simples relação entre as variáveis, sem incluir na explicação o sentido da ação para os tomadores de decisão, aproxima o estudo de Blau às "leis gerais" nomológicas (Turner, 1977; Hedström, 2005).

Um pressuposto importante nas abordagens $\mathrm{N}$-grande é a da homogeneidade das unidades observadas. Se duas unidades sofrem o mesmo tratamento, deveríamos observar a mesma variação na variável dependente. Fora do contexto laboratorial, onde experimentos não podem ser controlados, é difícil obtermos unidades perfeitamente homogêneas. Assim, um procedimento comum é a identificação de variáveis de "controle" que poderiam explicar parte da variação, de forma independente das variáveis explicativas ligadas às hipóteses a serem testadas. A atribuição dessas variáveis de controle às observações não é aleatória, mas correlaciona-se fortemente com as outras variáveis centrais na análise. Por exemplo, o que realmente significa a variável de controle "continente" quando tentamos prever a estabilidade de um regime político? Seria possível pensar o Brasil "fora" da América Latina?

Uma das regras populares das abordagens $\mathrm{N}$ -grande é a da busca de observaçôes que levem à variação da variável dependente (King, Keohane, et al., 1994). Ragin (2006) é contrário a essa estipulação, afirmando que o mesmo comportamento pode ser gerado por processos distintos e, portanto, apenas a descrição profunda dos mecanismos causais realmente em funcionamento pode explicitar como as variáveis explicativas levam ao comportamento observado. Em contrapartida, a abordagem $\mathrm{N}$-grande exige que se assuma que aquelas variáveis não observadas não sejam consideradas relevantes para a explicação (contrariando o pressuposto R.iv.

Estudos de caso (N-pequeno) tendem a exaurir as informaçóes disponíveis que se relacionam a uma observaçáo de interesse. Por outro lado, estudos estatísticos ( $\mathrm{N}$-grande) tendem a coletar amplas amostras, com pretensão de representatividade de uma população. Manicas (2006) observa que enquanto a abordagem qualitativa preserva a integridade do objeto estudado, concentrando a coleta ao máximo de informaçōes relevantes para a sua explicação, os estudos estatísticos privilegiam a coleta de amostras dispersas, assumindo que os diversos casos em análise se relacionam entre si pela mediação das variáveis de interesse.

O contraste entre métodos quali e quanti nessa seção privilegiou as diferenças "vocacionais" das distintas abordagens. Na próxima seção, analiso como os pressupostos intrínsecos dos modelos quantitativos e estatísticos podem levar à problematização das interpretaçôes usuais desses estudos. Passo, assim, aos pressupostos "limitaçōes" e "problemas dos métodos estatísticos", que desembocam em uma maior interdependência entre as abordagens.

\section{Limitaçóes e problemas na abordagem de $\mathrm{N}$-grande}

Diversos pressupostos assumidos pelos métodos quantitativos e multivariados podem ser frustrados no seu conjunto e em suas ferramentas específicas, levando o pesquisador à reconsideração do instrumento e à solicitação de auxílio a uma abordagem N-pequeno. São casos em que o desenho de pesquisa pode ser considerado "indeterminado" (por imposição do modelo estatístico em uso) ou por graves violações na construção ou pela análise dos dados.

A disponibilidade de dados suficientes para a inferência causal (frustrando o pressuposto R.i) é obviamente a primeira conjectura a ser contemplada. Eventos raros (por exemplo, revoluçōes) são ótimos candidatos a abordagens N-pequeno. Existem, no entanto, problemas potenciais subjacentes às abordagens $\mathrm{N}$-grande que podem se beneficiar de abordagens $\mathrm{N}$-pequeno. De forma mais dramática, como aponta Burke (1992), as abordagens quantitativas pressupõem a estabilidade do significado dos conceitos no tempo e a comparabilidade em contextos distintos. "Classe média", para citar um exemplo, pode ter conotaçôes distintas em momentos diferentes, assim como a variável "alfabetizado" 
pode ser interpretada diversamente dependendo do contexto. Em geral, o instrumento de coleta (como o questionário) pode trazer uma série de problemas na sua validação quando aplicado em pontos geográficos e temporais distintos de sua aplicação original. Em contrapartida, Burke sugere que se adote a etnografia como método de pesquisa, uma vez que permite acesso privilegiado às práticas concretas dos atores sociais.

Abordagens $\mathrm{N}$-grande pressupõem uma ordem causal entre as variáveis independente e dependente. Entretanto, se esta última pode também influenciar a primeira, temos um problema de endogeneidade que encontra limitações de tratamento, dependendo da amostragem disponível. Halpern (1993), por exemplo, investigou em livros, jornais e discursos em que medida as ideias dos líderes comunistas do Leste europeu antecediam a adoção de políticas filo-stalinistas. O problema imposto pela análise é que a adoção dessas políticas poderia ter sido forçada pela ocupação soviética nesses países, e assim a visão das lideranças seria uma racionalização retrospectiva para legitimar as decisōes anteriores. Ainda que a autora tenha levado em conta a sequência de eventos (por exemplo, a existência de um discurso antes ou depois da adoção de determinada política), não conseguiria estabelecer se tal líder estava ou não predisposto à adoção dessa política de forma independente. Para tanto, Halpern foi obrigada a adotar uma abordagem $\mathrm{N}$-pequeno e trazer como casos de controle países que tinham desenvolvido seus próprios regimes comunistas, sem a intervenção soviética. Halpern, então, identificou que tanto a China como a Iugoslava adotaram políticas semelhantes às stalinistas, sendo o primeiro país de forma independente e o segundo, a despeito da União Soviética.

Poderíamos argumentar que o exemplo de Halpern leva-nos à abordagem $\mathrm{N}$-pequeno por conta da raridade de observaçôes. Tomemos então o problema colocado por Przeworski (2007) quanto à relação entre regime (democrático ou ditatorial) e crescimento econômico. $\mathrm{O}$ autor mostra que a analogia do "experimento" nas ciências sociais é falha, porque as observações não recebem tratamentos aleatórios, rompendo os pressupostos usuais de métodos multivariados, como a regressão linear (Blalock, 1979).
Na melhor das hipóteses, poderíamos falar de "quase experimentos", onde a "história" estabelece valores às unidades. Segundo seu estudo, existe uma grande coincidência entre "ditaduras" e "pobreza", o que dificulta o entendimento dos processos que relacionam regime político a desenvolvimento econômico. Przeworski aponta a dificuldade de se estabelecer uma ordem causal entre as variáveis. Como saber se a mesma elite que foi educada para implementar a democracia não recebeu também treinamento para estabelecer instituiçōes que levem ao crescimento econômico? $\mathrm{Ou}$, se as elites treinadas para promover golpes militares não receberam uma carga ideológica para desconfiar dos mecanismos econômicos de mercado? Quando a questáo da endogenia não é solucionada pela análise estatística, o pesquisador, afirma Przeworski, deve apelar para uma abordagem $\mathrm{N}$-pequeno que possibilite o pareamento entre as observaçōes, a fim de se aproximar ao máximo de unidades que possam ser consideradas homogêneas. Como exemplo inspirador de futuras pesquisas, o autor cita o texto de Yashar (1997), um empenho para explicar o processo histórico que levou a Costa Rica a adotar a democracia, enquanto a Guatemala enveredou para a ditadura.

Podemos elencar críticas aos métodos estatísticos quando se trata de abordagens mais populares, mas isso não significa a falência do método. Segundo Ragin (2006), a maioria dos estudos quantitativos de política comparada utiliza modelos de regressão lineares, cuja fundamentação teórica da interação das variáveis explicativas não é frequente. Em contrapartida, os pesquisadores quanti criam uma espécie de "competição" entre as variáveis dispostas em modelos multivariados, a fim de encontrar fatores que expliquem da melhor forma a variável dependente, sem dar a devida atenção às relações entre elas. Mesmo quando existe uma teorização, os pesquisadores entendem a interação com "produto" das variáveis explicativas. A linearidade dos modelos, principalmente quando se trata de observaçōes longitudinais, acaba assumindo a linearidade temporal dos processos sociais (Abbott, 1988). Esta mesma crítica é corroborada por Tilly (2001), quando afirma que a emersão de processos sociais não se dá de forma linear: alguns processos são lentos e demoram às vezes séculos para expres- 
sar seus efeitos. A escolha da abordagem N-pequeno nesse contexto é recomendada por sua vocação em explicitar de forma menos "automática" as diversas temporalidades em curso na explicação de um processo causal, e por deslocar a explicação da "variável” ao "processo" (Ragin, 2006).

Ragin critica ainda a forma "automática” e "irrefletida” de se construir, numa abordagem $\mathrm{N}$-grande, populaçōes adotando como fronteiras as categorias naturalizadas pelos próprios atores sociais interessados. Como exemplo contrastante, vale lembrar como Abbott (2005) entende o embate dos profissionais no campo da medicina no século XIX nos Estados Unidos. Se ele tivesse se restrito à população de médicos, perderia de vista outros profissionais que exerciam atividades compatíveis, como curandeiros e acupunturistas. Em suma, sugere-se que ao utilizar uma abordagem $\mathrm{N}$-grande se leve em consideração o método $\mathrm{N}$-pequeno para uma melhor adequação da construção da população (e correspondente amostra) à teoria em teste. Essa ponderação leva a uma convergência entre Ragin (2006) e King, Keohane et al. (1994), em relação à decisão de estabelecimento das fronteiras da população: devemos incluir nos estudos indivíduos, cuja variação na variável dependente seja plausível.

\section{Justaposição e síntese de métodos quanti e quali}

$\mathrm{Na}$ seção anterior foram descritas diversas situaçôes onde se justifica a combinação de abordagens quali (N-pequeno) e quanti (N-grande), ou mesmo o abandono de uma em favor da outra. Preliminarmente, creio que, quando possível, a abordagem quali deve anteceder o método $\mathrm{N}$-grande, já que ajuda a explicitar os mecanismos causais que vão influenciar na coleta de dados e na escolha do ferramental estatístico da abordagem $\mathrm{N}$-grande.

É também possível, embora seja raro, identificar análises quantitativas que auxiliam o estabelecimento da validade de estudos originalmente qualitativos. Stinchcombe (2005), por exemplo, mostra a dificuldade de se entender as origens do movimento sindicalista norte-americano através de entrevistas individuais, uma vez que elas poderiam silenciar as possíveis influências do sindicalis- mo alemão ou japonês. Isto é, seria "politicamente incorreto" entender o sindicalismo nesses países como atores centrais na pesquisa, tendo em vista a Segunda Guerra Mundial. A estratégia analítica de Stinchcombe foi recuperar os índices de greve e identificar os picos de conflito no pré-guerra (2005, p. 138). Assim pode desenvolver a pesquisa em periódicos nas datas respectivas das greves, para entender os discursos utilizados e as influências alemãs e japonesas. A pesquisa quantitativa, portanto, ajuda a identificação de momentos e locais que podem vir a ser o foco de análises qualitativas complementares, aumentando a validade do estudo, e não necessariamente, é importante frisar, sua generalização. Se a validade de um estudo não está bem estabelecida, a generalização torna-se irrelevante. Desse ponto de vista, o estudo quantitativo não é utilizado para o estabelecimento de "efeitos causais", mas para mapear a variação de grandezas de interesse (Abbott, 1998). Mesmo regressōes podem ser interpretadas como "descrições" e não necessariamente como "previsōes".

Proponho que essa colaboração de abordagens se dê de forma pendular: podemos também retornar à abordagem $\mathrm{N}$-pequeno após realizar as análises $\mathrm{N}$ -grande. Creswell identifica três usos possíveis para métodos mistos: triangulação, sequenciamento, e transformação. O primeiro, realizando a triangulação dos dados, busca aumentar a validade das conclusōes. $\mathrm{O}$ segundo implica em utilizar um método antes do outro como estratégia de desenho de pesquisa. Por exemplo, métodos quali podem ser utilizados em situações onde pouco fora pesquisado sobre o objeto de interesse (Creswell, 2008). Por fim, o método transformativo envolve a coleta conjunta de dados quali e quanti no desenho de pesquisa.

Huff (2008) sintetiza as vantagens e as desvantagens dos métodos mistos em relação às abordagens tradicionais. Para a autora, os métodos mistos seriam mais pragmáticos em combinar materiais com o objetivo de alcançar um equilíbrio ótimo entre abordagens quanti e quali. Estudos quanti completados por estudos quali podem fornecer maior potencial de interpretação dos fenômenos, principalmente ao agregar a percepção dos indivíduos no desenho de pesquisa. $\mathrm{O}$ inverso garante uma generalização para além do contexto específico de análise, o que im- 
plica uma maior amplitude do estudo. Idealmente, ao combinar abordagens quali e quanti, os pesquisadores evitariam as fragilidades próprias de cada método. No entanto, estudos baseados em métodos mistos ainda correm o risco de serem criticados pela superficialidade da análise se comparados aos métodos tradicionais de construção de conhecimento nas distintas comunidades científicas.

Ragin (1989) é provavelmente um dos principais defensores de superação dessa divisão. Ele propõe que utilizemos a análise buleana para a descrição de processos causais. Ou seja, tratar as variáveis como dicotômicas e entender a maneira pela qual configuraçôes de variáveis explicam o comportamento observado. Existem algumas distinçôes importantes dessa metodologia comparada àquela comumente utilizada com ferramentas multivariadas. Em primeiro lugar, é comum a ocorrência nas ciências sociais da assimetria causal entre as variáveis incluídas na construção das matrizes de respostas possíveis. Essa possibilidade contrasta com os métodos multivariados, em que o favorecimento de correlações assume a simetria, dificultando o estabelecimento de ordem causal. Em segundo lugar, é possível estabelecer uma ordem cronológica causal entre os eventos, revelando os processos históricos que levam ao surgimento da observação. Esses processos admitem equifinalidade, ${ }^{11}$ explicitando assim efeitos multicausais e dispensando o imperativo de variação da variável dependente para a construção de teorias (em contraste com o estudo de King, Keohane, et al., 1994). Ragin pretendeu aprimorar a distinção entre condições necessárias e condições suficientes em um processo causal, o que é bastante adequado quando se trata de identificar todos os fatores que mutuamente explicam o fenômeno e coletivamente são exclusivos na explicação. Isso possibilita considerar irrelevantes as variáveis não observadas e obter o máximo de alavancagem com economia de recursos. Em elaboração recente, Ragin (2008) propõe a utilização de fuzzy-sets, isto é, a inclusão de variáveis estocásticas.

\section{Conclusão}

Revimos no decorrer deste texto a separação entre abordagens quali (N-pequeno) e quanti (N- -grande). Com efeito, houve uma explícita escolha em direção à centralidade de "mecanismos causais", com o objetivo de diminuir a influência das "guerras paradigmáticas" sobre a discussão (Morgan, 2007).

Sob a perspectiva de "mecanismos causais", mostrei como as abordagens são complementares e mesmo interdependentes: o desenho de pesquisa com uma abordagem $\mathrm{N}$-grande depende de uma imersão em descriçôes e explicaçóes de casos que utilizam métodos quali. Em diversas ocasióes, roga-se o abandono da pretensão generalizante de amplo alcance das abordagens " $\mathrm{N}$-grande".

Apontei também algumas críticas às abordagens multivariadas mais comuns, incluindo o recorrente problema de tratamento "linear" da temporalidade. Vale uma ressalva: as técnicas quantitativas e estatísticas não se limitam aos modelos lineares, mas já abarcam possibilidades que tratam a temporalidade de outras formas, como por exemplo nas técnicas de modelagem agent-based (Macy e Willer, 2002). Apresentei ainda possíveis alternativas às técnicas multivariadas, incluindo a análise buleana proposta por Ragin.

Não pretendi aqui advogar o abandono das técnicas multivariadas e de outras técnicas associadas a $\mathrm{N}$-grande. Ao contrário, para muitas comunidades científicas a inferência causal vinculada às análises multivariadas continuará a ser norteadora para a construção de conhecimento científico. $\mathrm{O}$ que proponho como alternativa é um processo heurístico de "idas e vindas" (Huff, 2008). Essa abordagem torna-se necessária principalmente quando o pesquisador se defronta com modelos incompletos, em que o teste dos caminhos causais através da abordagem quanti esgota-se. Tomando as palavras de King, Keohane et al. (1994), não se pretende defender essa ou aquela técnica, mas propiciar ao pesquisador ferramentas que maximizem a alavancagem da pesquisa.

As limitaçôes, evidentemente, são de ordens diversas. Em primeiro lugar, assumiram-se a comparabilidade e a generalização como pressupostos do conhecimento científico. Não há justificativa para que esses pressupostos sejam universalmente aceitos, e nem mesmo a possibilidade que sejam sempre aplicados. Por exemplo, nos estudos de sistema-mundo, não é possível obter uma comparabilidade 
quando tratamos de um único caso (Collins, 1984; Wallerstein, 2004). De forma correlata, poderíamos suspeitar que as observações sobre casos aparentemente independentes sugiram epifenômenos ${ }^{12}$ quando levamos em consideração o funcionamento de sistemas mais amplos (Tilly, 1984). Em segundo lugar, ao buscar caminhos causais, corre-se o risco de enfatizar mecanismos, com menor atenção ao contexto histórico. Como aponta Reed (2012), a abordagem de mecanismos pode enfrentar obstáculos em dialogar com a sociologia histórica, que enfatiza a interpretação.

Além disso, evitei abordar diretamente os debates que lidam com a síntese entre os níveis macro e micro (Alexander, 1987) ou entre agência e estrutura (Bourdieu, 1977; Giddens, 1986). Por um lado, os esforços de síntese (micro/macro e estrutura/agência) são importantes, na medida em que propõem conceitos que informam estratégias metodológicas. Por outro, grande parcela desse debate tende a enfatizar a taxonomia subjacente às teorias, dando menor ênfase às implicações metodológicas. Tomado de forma exagerada, uma síntese suficientemente ampla sempre será capaz de encaixar os achados empíricos em sua taxonomia, mas isso não significa que poderá explicar a existência de variação entre os casos.

Entretanto, cabe aos pesquisadores a demonstração da utilidade dessa abordagem aos projetos de síntese, para que não fique restrita a uma comunidade limitada de estudiosos (frequentemente ligados ao mainstream da ciência política e da sociologia norte-americana). Esforços recentes de tradução da lógica dos mecanismos causais para teorias que vão além das abordagens macroestruturais da ciência política, ou da escolha racional, já podem ser encontrados; exemplo disso são as tentativas de investigação do conceito de habitus como mecanismo mediador entre campo e prática (Vaughan, 2009).

\section{Notas}

1 Restrinjo o escopo de uma orientação "positivista" para as pesquisas que buscam representar fenômenos em variáveis e exploram as possíveis explicaçôes para uma variável de interesse ("variável dependente”). Ver
Abbott (1997), para uma definição semelhante.

2 Pesquisadores que se afiliam à perspectiva interpretacionista são comumente associados à tradição iniciada por Wihelm Dilthey. É central a essa abordagem o conceito de Verstehen: a compreensão se dá com base na empatia com os motivos e desejos do ator social que o pesquisador busca capturar em sua pesquisa. Desse ponto de vista, os pesquisadores defendem que a subjetividade do ator social e, consequentemente, sua interpretação do contexto devem ser centrais no esforço de pesquisa. $\mathrm{O}$ pesquisador nos convida para um "passeio" através de suas percepçōes e análises de notas de campo e nos pede confiança na sua sensibilidade para legitimar a coleta de seus dados. Não existe uma pretensão de replicabilidade dentro dessa tradição, o que introduz atritos inevitáveis no contato com pesquisadores que buscam o estabelecimento de generalizações. Ao contrário, a exterioridade da comparação trairia o acesso hermenêutico ao objeto.

3 Essa discussão também está no centro da sociologia weberiana, geralmente discutidas sob a égide epistemológica. A estratégia weberiana é geralmente articular a compreensão do sentido da ação do ator à construção de tipos-ideais. Nesse sentido, Weber também fora atacado por afastar-se das abordagens históricas tradicionais.

4 Para uma consideração crítica das lógicas distintas de explicação e compreensão na sociologia, ver Ianni (1990). Para uma reflexão do ponto de vista da formação de novos pesquisadores, ver Cano (2012).

5 Wallerstein (2010) contrasta o "reducionismo epistemológico" - a ideia de que o todo pode ser explicado pela agregação de suas partes - com a "epistemologia emergentista" - a ideia de que efeitos sistêmicos não podem ser previstos e explicados pelas partes. Ver também Sawyer (2011) para uma crítica análoga a Wallerstein. A abordagem que adoto ao longo deste artigo busca ao máximo abarcar essas sugestōes, principalmente ao elencar exemplos empíricos da ciência política, cujos mecanismos causais remetem principalmente a mudanças estruturais macro.

6 Para a integração do nível macro, interacional e individual, ver também Mouzelis (1995).

7 A Hume também é atribuída a proposição do "efeito causal", ligada à ideia de que "conjunção constante" (correlação) entre variáveis é suficiente para o estabelecimento de causação.

8 De forma menos frequente, encontramos estudos desenhados a partir de causas preestabelecidas, mantendo os efeitos em aberto. 
9 Ver Eisenhardt (1989) e Vaughan (1992), como sugestôes do método de caso para a construção indutiva de teoria.

10 Esse ponto ficará evidente ao final do artigo, quando recuperarei a crítica de Wallerstein ao método comparado.

11 Equifinalidade refere-se à ideia que o mesmo efeito pode ser gerado por caminhos causais distintos.

12 Um epifenômeno é um fenômeno secundário, que é derivado e sempre acompanhado do fenômeno principal.

\section{BIBLIOGRAFIA}

ALEXANDER, J. C. (1987), "Introduction". The micro-macro link, pp. 1-42, Berkeley, University of California Press.

ABBOTT, A. (1988), "Transcending general linear reality”. Sociological Theory, 6: 169-186.

(1997), "Seven types of ambiguity". Theory and Society, 26 (2): 357-399.

(1998), "The causal devolution". Sociological Methods and Research, 27 (2): 148181.

(2001), Chaos of disciplines. Chicago, University of Chicago Press.

(2005), "Linked ecologies: states and universities as environments for professions". Sociological Theory, 23: 245-274.

BECKER, H. S. (1998), Tricks of the trade: How to think about your research while you're doing it. Chicago, University of Chicago Press.

BLALOCK, H. M. (1979), Social statistics. Nova York, McGraw-Hill.

BLAU, P. M. (1970), "A formal theory of differentiation in organizations". American Sociological Review, 35 (2): 201-218.

BOURDIEU, P. (1977), Outline of a theory of practice. Cambridge, Cambridge University Press.

(1986), "Lillusion biographique". Actes de la Recherche en Sciences Sociales, 62 (1): 69-72.

(2006), A distinção: a crítica social do julgamento. São Paulo, Edusp.

BOURDIEU, P.; CHAMBOREDON, J. C. \& PASSERON, J. C. (2004), O ofício de sociólogo: metodologia da pesquisa na sociologia. Petrópolis, RJ, Vozes.
BURKE, P. (1992), History and social theory. Londres, Polity Press.

CAMIC, C. \& GROSS, N. (1998), "Contemporary developments in sociological theory: current projects and conditions of possibility". Annual Review of Sociology, 24: 542-576.

CANO, I. (2012), "Nas trincheiras do método: o ensino da metodologia das ciências sociais no Brasil”. Sociologias, 14 (31): 94-119.

COLEMAN, J. (1990), Foundations of social theory. Cambridge, Harvard University Press.

COLLINS, R. (1988), "Statistics versus words". Sociological Theory, 2: 329-362.

COUlON, A. (1995), Etnometodologia. Petrópolis, RJ: Vozes.

CRESWELL, J. W. (2008), Research design: qualitative, quantitative, and mixed methods approaches. Thousand Oaks, CA, Sage.

DENZIN, N. \& LINCOLN, Y. (2005), The Sage handbook of qualitative research. $3 \mathrm{ed}$. Thousand Oaks, CA, Sage.

DIMAGGIO, P. (1995), "Comment on 'What theory is not'". Administrative Science Quarterly. 40: 391-397.

EISENHARDT, K. (1989), "Building theories from case study research". The Academy of Management Review, 14: 532-550.

ELSTER, J. (1994), Peças e engrenagens das ciências sociais. Rio de Janeiro, Relume Dumará.

GERRING, J. (2007), "The case study: what it is and what it does", in C. Boix e S. C. Stokes (eds.). The Oxford handbook of comparative politics, Nova York, Oxford University Press, pp. 90-122.

GIDDENS, A. (1986), The constitution of society: outline of the theory of structuration. Berkeley, University of California Press.

GOLDTHORPE, J. H. (2007), "The uses of history in sociology: reflections on some recent tendencies", in On sociology, Stanford Univertity Press, pp. 21-38.

GOODWIN, J. \& HOROWITZ, R. (2002), “Introduction: the methodological strengths and dilemmas of qualitative sociology". Qualitative Sociology, 25 (1): 33-47.

GROSS, N. (2009), "A pragmatist theory of social mechanisms". American Sociological Review, 
74: 358-379.

HALPERN, N. P. (1993), "Creating socialist economies: Stalinist political economy and the impact of ideas", in J. Goldstein e R. O. Keohane (eds.), Ideas and foreign policy: beliefs, institutions, and political change. Ithaca, NY, Cornell University Press, pp. 87-110.

HEDSTRÖM, P. (2005), Dissecting the social: on the principles of analytical sociology. Cambridge, UK, Cambridge University Press.

HEDSTRÖM, P. \& YLIKOSKI, P. (2010), "Causal mechanisms in the social sciences". Annual Review of Sociology, 36: 49-67.

HUFF, A. S. (2008), Designing research for publication. Thousand Oaks, CA, Sage.

IANNI, O. (1990), "A crise dos paradigmas na sociologia: problemas de explicação". Revista Brasileira de Ciências Sociais, 13: 90-100.

KING, G.; Keohane, R. O. et al. (1994), Designing social inquiry: scientific inference in qualitative research. Princeton, Princeton University Press.

KNORR-CETINA, K. (1981), The manufacture of knowledge: an essay on the constructivist and contextual nature of science. Oxford, Pergamon Press.

KNORR-CETINA, K. \& MULKAY, M. (1983), Introduction: emerging principles in social studies of science. Berlim, Bibliothek der Universität Konstanz.

LEE, R. E. \& WALLERSTEIN, I. (2000), "Structures of knowledge". The Blackwell Companion to Sociology, pp. 228-235.

LITTLE, D. (1998), Microfoundations, method and causation: on the philosophy of the social sciences. New Brunswick, NJ, Transaction Publishers. (2000), "Analytical Sociology and the Rest of Sociology”. Sociologica, 6 (1). Disponível em em <http://www.sociologica.mulino.it/ doi/10.2383/36894>.

MACY, M. W. \& Willer, R. (2002), "From factors to actors: computational sociology and agent-based modeling". Annual Review of Sociology, 28: 143-66.

MAHONEY, J. \& Goertz, G. (2006), "A tale of two cultures: contrasting quantitative and qualitative research”. Political Analysis, 14: 227 249.
MANICAS, P. T. (2006), A realist philosophy of social science: explanation and understanding. Cambridge, UK, Cambridge University Press.

MANZO, G. (2010), "Analytical sociology and its critics". European Journal of Sociology, 51 (1): 129-170.

MARQUES, E. (2007), "Os mecanismos relacionais”. Revista Brasileira de Ciências Sociais, 22 (64): 157-161.

MERTON, R. K. (1936), "The unanticipated consequences of purposive social action". Am. Sociol. Review, 1: 894-904.

MORGAN, D. (2007), "Paradigms lost and pragmatism regained". Journal of Mixed Methods Research, 1 (1): pp. 48-76.

MORGAN, S. L. \& Winship, C. (2007), Counterfactuals and causal inference: methods and principles for social research. Cambridge, UK, Cambridge University Press.

MOUZELIS, N. (1995), Sociological theory: What went wrong? Diagnosis and remedies. Londres, Routledge.

PARSONS, T. (1951), The social system. Glencoe, Free Press.

(1959), "The school class as a social system". Harvard Educational Review, 29: 297 318.

PRZEWORSKI, A. (2007), "Is the science of comparative politics possible?", in C. Boix e S. C. Stokes (eds.), The Oxford handbook of comparative politics. Nova York, Oxford University Press, pp. 147-171.

RAGIN, C. C. (1989), The comparative method: moving beyond qualitative and quantitative strategies. Berkley, CA, University of California Press.

(2006), "How to lure analytic social science out of the doldrums: some lessons from comparative research". International Sociology, 21: 633-646.

\section{(2008), Redesigning social inquiry:} fuzzy sets and beyond. Chicago, University of Chicago Press.

RAGIN, C. C. \& BECKER, H. S. (1992), What is a case? Exploring the foundations of social inquiry. Cambridge/New York, Cambridge University Press. 
REED, I. A. (2012), "Analytical sociology: appreciation and ambivalence". Sociologica, 6 (1). Disponível em <http://www.rivisteweb.it/ doi/10.2383/36901>.

REICHARDT, C. \& Cook, T. (1979), "Beyond qualitative versus quantitative methods", in $\mathrm{T}$. Cook e C. Reichardt (eds.), Qualitative and quantitative methods in evaluation research, Thousand Oaks, CA, Sage, pp. 7-32.

RINGER, F. K. (2000), Max Weber's methodology: the unification of the cultural and social sciences. Cambridge, MA, Harvard University Press.

SAWYER, K. (2011), "Conversation as mechanism: emergence in creative groups", in Pierre Demeulenaere (ed.), Analytical sociology and social mechanisms, Cambridge/Nova York, Cambridge University Press.

SEWELL JR., W. H. (2005), Logics of history: social theory and social transformation. Chicago, University of Chicago Press.

SKIDELSKY, E. (2009), Ernst Cassirer: the last philosopher of culture. Princeton, Princeton University Press.

SKOCPOL, T. (1979), States and social revolutions: a comparative analysis of France, Russia, and China. Cambridge, UK, Cambridge University Press.

SUTTON, R. \& STAW, B. (1976), "What theory is not". Administrative Science Quarterly, 40: 371-384.

TEDDLIE, C. \& TASHAKKORI, A. (2003), "Major issues and controveries in the use of mixed methods in the social and behvioral sciences". Handbook of mixed methods in social \& behavioral research, pp. 3-50.

TILLY, C. (1984), Big structures, large processes, huge comparisons. Nova York, Russell Sage Foundation. (2001), "Mechanisms in political processes". Annual Review of Political Science, 4: $21-41$.

TURNER, S. P. (1977), "Blau's theory of differentiation: Is it explanatory?. The Sociological Quarterly, 18 (1): 17-32.

WALLERSTEIN, I. (2004), World-systems analysis: an introduction. Durham, Duke University Press.
(2010), “Organizers' opening remarks”, in R. E. Lee (ed.), Questioning Nineteenth-century assumptions about knowledge: reductionism, Nova York, Suny Press, vol. 2.

WOODWARD, J. (2002), "What is a mechanism? A counterfactual account". Philosophy of Science, 69 (3): 366-377.

VAUGHAN, D. (1992), “Theory elaboration: the heuristics of case analysis", in C. C. Ragin e H. S. Becker (eds.), What is a case? Exploring the foundations of social inquiry, Cambridge, UK, Cambridge University Press, pp.173-204 (2009), "Analytic ethnography", in P. Hedstrom e P. Bearman (eds.), The Oxford handbook of analytical sociology, pp. 688-711.

YASHAR, D. J. (1997), Demanding democracy: reform and reaction in Costa Rica and Guatemala, 1870s-1950s. Stanford, CA, Stanford University Press. 


\section{DECISÕES ENTRE PESQUISAS \\ QUALIE QUANTISOB A \\ PERSPECTIVA DE MECANISMOS \\ CAUSAIS}

\section{Charles Kirschbaum}

Palavras-chave: Metodologias quali-quanti; Mecanismos causais; Mecanismos sociais.

A escolha por métodos quali ou quanti é tradicionalmente mediada pelo debate entre paradigmas de construção de conhecimento. Geralmente, os livros-texto em metodologia de pesquisa associam os métodos quali ao paradigma construtivista-fenomenológico, enquanto os métodos quanti são em geral associados a pretensões positivistas. Esse artigo explora o processo de decisão entre metodologias sob a perspectiva dos mecanismos causais, que vêm sendo desenvolvidos sob múltiplas orientações. Buscamos aprofundar a discussão sobre as implicações da escolha de um determinado método (quali, quanti ou misto), examinando suas possíveis aplicações nas ciências sociais.

\section{DECIDING BETWEEN QUALI AND QUANTI RESEARCH FROM THE PERSPECTIVE OF CAUSAL MECHANISMS}

\section{Charles Kirschbaum}

Keywords: Quali-quanti methodologies; Causal mechanisms; Social mechanisms.

Decision in favor of quali or quanti methods is traditionally mediated by the debate between paradigms of knowledge construction. In general, the text-books on methodology of the research associate the quali methods to the constructivistphenomenological paradigm, whereas the quanti methods are usually associated to positivist pretensions. This article explores the process of decision between methodologies from the perspective of the causal mechanisms, which are being developed under multiple orientations. It also seeks to deepen the discussion over the various implications of choosing a certain method (quali, quanti, or mixed), examining their possible applications in the social sciences.

\section{DECISIONS ENTRE RECHERCHES QUALIET QUANTI SOUS LA PERSPECTIVE DE MECANISMES CAUSAUX}

\section{Charles Kirschbaum}

Mots-clés: Méthode quali quanti; Mécanismes causaux; Mécanismes sociaux.

Traditionnellement, le débat entre les paradigmes de construction du savoir sert de médiateur pour le choix des méthodes quali ou quanti. Généralement, les livres-textes sur la méthodologie de recherche associent les méthodes quali au paradigme constructiviste-phénoménologique, tandis que les méthodes quanti sont en général associées à des prétentions positivistes. Cet article explore le processus décisionnel entre méthodologies sous la perspective des mécanismes causaux qui sont développés sous de multiples orientations. Nous cherchons à approfondir la discussion sur les implications du choix d'une méthode déterminée (quali, quanti ou mixte) en examinant ses possibles applications dans les sciences sociales. 